\title{
Depiction of global trends in publications on mobile health
}

\author{
Shahla Foozonkhah ${ }^{1}$ and Leila R. Kalankesh ${ }^{2,3}$
}

1. Department of Health Information Technology Assessment, Standardization and Tariff Setting, Iranian Ministry of Health and Education, Tehran, Iran; 2. Tabriz Health Services Management Research Center, Tabriz University of Medical Sciences, Tabriz, Iran; 3. Department of Health Information Technology, School of Management and Medical Informatics, Tabriz University of Medical Sciences, Tabriz, Iran.

Corresponding author: Leila R. Kalankesh, e-mail: Lrkalankesh@tbzmed.ac.ir

Co-author: SF: sh.foozonkhah@health.gov.ir

Received: 04-04-2017, Accepted: 20-06-2017, Published online: 18-07-2017

doi: $10.14202 / \mathrm{IJOH} .2017 .42-45$ How to cite this article: Foozonkhah S, Kalankesh LR. Depiction of global trends in publications on mobile health. Int J One Health 2017;3:42-45.

\section{Abstract}

Background: Variety of mobile health initiatives in different levels have been undertaken across many countries. Trends of these initiatives can be reflected in the research published in m-health domain.

Aim: This paper aims to depict global trends in the published works on m-health topic.

Materials and Methods: The Web of Science database was used to identify all relevant published papers on mobile health domain worldwide. The search was conducted on documents published from January 1898 to December 2014. The criteria for searching were set to be "mHealth" or "Mobile health" or "m health" or "m_health" or "m-health" in topics.

Results: Findings revealed an increasing trend of citations and publications on $\mathrm{m}$-health research since 2012. English was the first most predominant language of the publication. The US had the highest number of publication with 649 papers; however, the Netherlands ranked first after considering publication number in terms of countries population. "Studies in Health Technology and Informatics" was the source title with highest number of publications on mobile health topics.

Conclusion: Trend of research observed in this study indicates the continuing growth is happening in mobile health domain. This may imply that the new model of health-care delivery is emerging. Further research is needed to specify directions of mobile health research. It is necessary to identify and prioritize the research gaps in this domain.

Keywords: mHealth, mobile health, publication trend, research trend, scientometrics.

\section{Introduction}

Mobile health is "medical and public health practice supported by mobile devices, such as mobile phones, patient monitoring devices, personal digital assistants, and other wireless devices [1]." M-health as the biggest technology breakthrough of our time [2], is an umbrella term for describing the use of mobile telecommunication technologies to deliver healthcare and to support population health $[3,4]$. Although mobile technologies cannot carry drugs and healthcare providers, they can transfer health information in different ways [5]. Particularly m-health technologies have potential to be used for responding in both communicable and non-communicable disease burden in developing countries [4].

M-health technologies have proved to have benefit for both health-care professionals and patients. Health-care professionals can use m-health for patient monitoring, access to references, communication and consultation, clinical decision-making, information management, time management, health record

Copyright: Foozonkhah and Kalankesh. This article is an open access article distributed under the terms of the Creative Commons Attribution 4.0 International License (http://creativecommons.org/ licenses/ by/4.0/), which permits unrestricted use, distribution, and reproduction in any medium, provided you give appropriate credit to the original author(s) and the source, provide a link to the Creative Commons license, and indicate if changes were made. The Creative Commons Public Domain Dedication waiver (http:// creativecommons.org/ publicdomain/zero/1.0/) applies to the data made available in this article, unless otherwise stated. access and maintenance, and medical education [6]. When mobile health initiative are used by public and patients, they can facilitate self-care and self-management [7].

Evidence shows an explosion of m-health activities worldwide [8]. Variety of mHealth initiatives in different levels have been undertaken across many countries. Some but not all of these countries are UK, Ghana, Senegal, France, Mexico, Estonia, Bangladesh, Bhutan, Malta, Greece, Vietnam, and Germany [1]. Therefore, trace of these initiatives can be reflected in the research published in m-health domain. As the mobile health technologies continue to grow, it seems inevitable to examine the research published in the literature in this field for characterizing its trend. This paper aims to depict global trends in the published works on m-Health topic.

\section{Materials and Methods}

\section{Source of data}

The Web of Science database was deployed to identify all relevant published papers on mobile health domain worldwide. The reason for selecting the Web of Sciences was the fact that its coverage in science is sufficiently comprehensive and it also includes the cited references for each paper.

\section{Study selection and data analysis}

Articles on topics of mobile health originating from different countries across the world were used for examining their scientific production in this field. The 
search was conducted on documents published from January 1898 to December 2014. Data collection was conducted in June 10, 2015. The criteria for searching were set to be "mHealth" or "Mobile health" or "m health" or "mHealth" or "m-health" in topics. The papers retrieved from query were filtered in terms of year, frequency of citations, country of origin, source title, and languages.

\section{Results}

Temporal trend of evidence on mobile health

Figure-1 shows overall number of publications on topics of mobile health worldwide by year. As it is evident there has been an increasing trend, in publishing on mobile health topics since 2010. This rise has occurred much more sharply since 2012.

\section{Top 10 productive countries}

As the statistics in Table-1 [9] indicate the United States is the most productive country in publishing research on topics of mobile health. The United Kingdom was ranked the second most productive country followed by China.

8 out of 10 top productive countries in m-health topics are among higher income countries except for China and India that are categorized as upper middle income and lower middle-income countries, respectively. Considering the number of publications per number of countries population, Netherlands holds the first rank followed by Australia and UK.

\section{Top 10 dominant languages}

Top 10 leading languages used for publications on topics of mobile health are English (5304), French (204), Russian (190), German (142), Swedish (32), Spanish (30), Korean (22), Japanese (22), Danish (21), and Norwegian (17). As it can be seen English is the most dominant language among the top 10 leading languages. Papers published in the English language (as the one holding the first place) is about 26 times higher than in French (placing in second place).

\section{Trend of citations}

Figure-2 depicts trend of citation to the published work in topics of mobile health. As it is evident from this graph, there has been growing increase in number of citations over time. In addition, number of citation has been increased sharply since 2012 .

\section{Top 10 productive journals}

Journals with the largest share in publishing $\mathrm{m}$-health topics are the journals such as studies in Health Technology and Informatics, JMIR, Voenno Meditsinsko Zhurnal, Lancet, Telemedicine and eHealth, and JMIR M-health and U-health (Figure-3).

\section{Discussion}

Temporal trend observed in research published in the field of mobile health implies a growing increase in this domain. The citations to these articles have been increased as well. Since 2012, the rise has occurred in

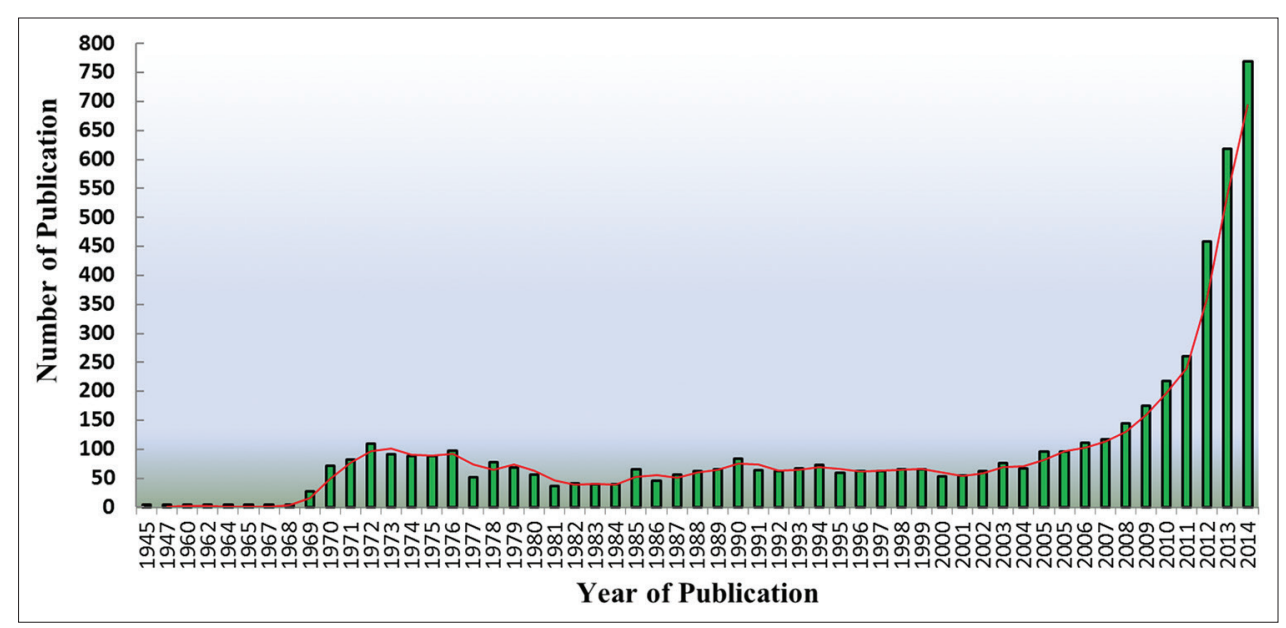

Figure-1: Temporal trend of publication on mobile health topic.

Table-1: Top 10 productive countries with publication on topics of Mobile Health.

\begin{tabular}{lccccc}
\hline Country & $\begin{array}{c}\text { Number of } \\
\text { documents }\end{array}$ & Population [9] & $\begin{array}{c}\text { Number of papers per } \\
\text { 1 million population }\end{array}$ & Economic rank & Optimized rank \\
\hline USA & 649 & $322,582,006$ & 2.01 & High income, OECD & 5 \\
UK & 202 & $63,489,234$ & 3.18 & High income, OECD & 3 \\
China & 129 & $1,393,783,836$ & 0.09 & Upper middle income & 9 \\
Canada & 107 & $35,524,732$ & 3.01 & High income, OECD & 4 \\
Australia & 85 & $23,630,169$ & 3.6 & High income, OECD & 2 \\
Spain & 76 & $47,066,402$ & 1.6 & High income, OECD & 6 \\
India & 65 & $1,267,401,849$ & 0.05 & Lower middle income & 10 \\
Netherlands & 63 & $16,802,463$ & 3.75 & High income, OECD & 1 \\
Germany & 61 & $82,652,256$ & 0.73 & High income, OECD & 8 \\
South Korea & 54 & $49,512,026$ & 1.09 & High income, OECD & 7 \\
\hline
\end{tabular}




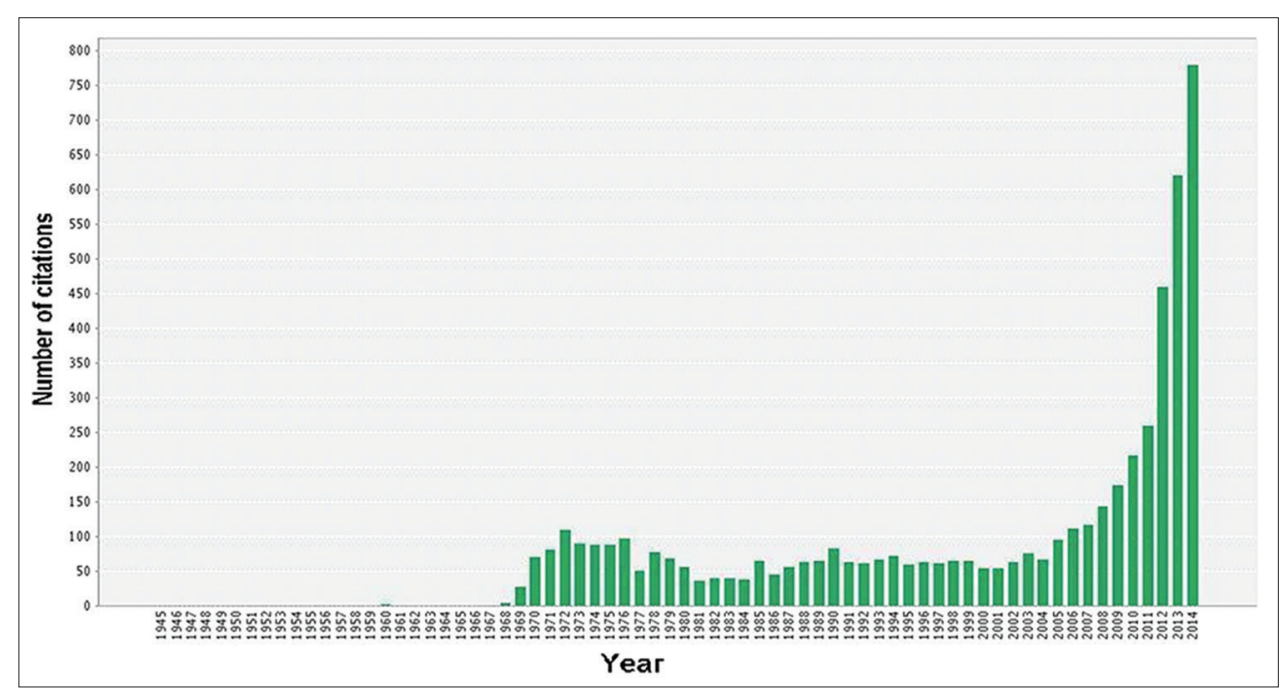

Figure-2: Number of citations to the papers published on m-health topics by year.

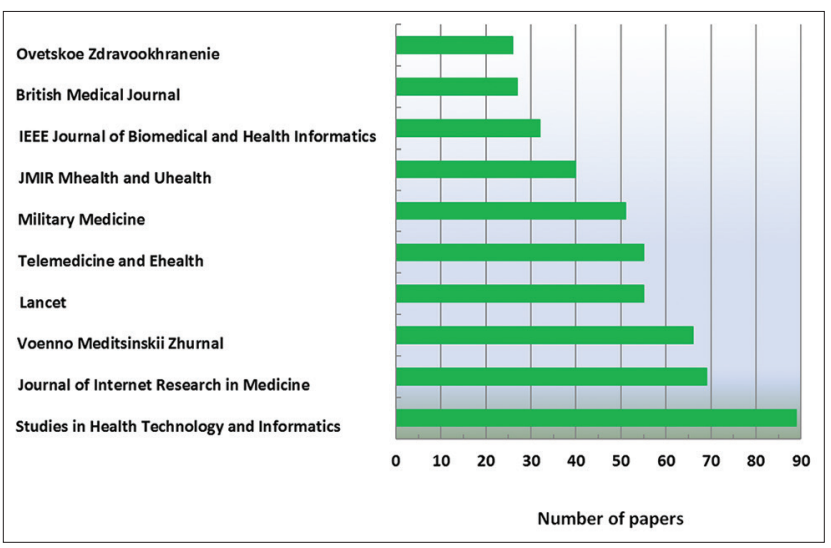

Figure-3: Top 10 productive journals in topic of mobile health.

both publications and citations much more sharply than before. This publication growth is in consistent with an increasing growth of m-health app market. As highlighted by the director of mHIMSS, "the mobile health market is experiencing one of the fastest growing areas in the health IT space" [10]. Evidence shows that mobile health market has a year-over-year growth rate of around 17\% since 2010 [11]. This growth has happened in all health-care areas including diagnostics, telemedicine, research, education, and interventions [12]. In fact, scope of mHealth applications has been expanded [13]. For instance, while growth in wearable technology is accompanied the m-health rise, m-health apps are used as an equipment supplement [14] for wearable that will soon become the cornerstone of future health-care strategies once the notion of smart healthy cities comes into the reality [15]. Moreover, attempts to integrate $\mathrm{m}$-health with electronic health records have been reported [16]. Mobile apps are also considered as one of the main platforms for empowering a broad spectrum of patients [17] and even some researchers have highlighted the necessity of developing strategic approach for making m-health solutions sustainable [18]. These are due to the fact that mobile devices support various technical functions and provide possibility of synchronized and asynchronized communication and services [19].

English was the predominant language of publication on $\mathrm{m}$-health topic as it has been reported in other domains [20-23]. This is in accordance with the fact that English is the dominant language of Science [24].

As it is evident from the statistics, North America (US and Canada), Australia, and Europe (UK, Netherlands, and Germany) have made the most contributions to this field. This is in line with the predominant language observed among papers as English is the primary language of science used among authors from those countries.

An increase observed in a number of citations may indicate greater acknowledgement of papers on mobile health topic. This may be attributed to the increasing interest emerged in m-health domain [25] as well as the increasing quality [26] of papers published in m-health domain. In fact, $\mathrm{m}$-health has been recognized as an independent research interest among academics and researchers. This is somehow reflected in a number of the papers published in the prestigious journals such as Journal of Internet Research in Medicine, Studies in Health Technology and Informatics, and Lancet.

\section{Conclusion}

Trend of research observed in this study indicates the continuing growth is happening in mobile health domain. Research on m-health appears to evolve as the field evolves. Further research is needed to specify directions of mobile health research worldwide and its evolution toward identifying the research and knowledge gaps in this domain.

\section{Authors' Contributions}

LRK and SF conducted the observations at the mobile health. SF reduced the data, and LRK performed the global trends in publications on mobile 
health analysis. LRK and SF drafted and revised the paper. Both authors discussed the results and implications and commented on the manuscript at all stages. Both authors read and approved the final manuscript.

\section{Acknowledgment}

This work has been done voluntarily without any financial support.

\section{Competing Interests}

The authors declare that they have no competing of interest.

\section{References}

1. World Health Organization. New Horizons for Health through Mobile Technologies: Based on the Findings of the Second Global Survey on eHealth; 2011.

2. Sebelius K. Mobile Healthcare is the Biggest Technology Breakthrough of our Time to address our Greatest National Challenge in mHealth Summit 2011. Washington DC: Department of Health and Human Services; 2011.

3. Steinhubl SR, Muse ED, Topol EJ. Can mobile health technologies transform health care? JAMA 2013;310:2395-6.

4. Kahn JG, Yang JS, Kahn JS. 'Mobile' health needs and opportunities in developing countries. Health Aff (Millwood) 2010;29:252-8.

5. Qiang C, Kuek SC. Mobile Application for the Health Sector. Washington, DC: ICT Sector Unit, World Bank; 2011.

6. Ventola CL. Mobile devices and apps for health care professionals: Uses and benefits. P T 2014;39:356-64.

7. Anderson K, Burford O, Emmerton L. Mobile health apps to facilitate self-care: A qualitative study of user experiences. PLOS One 2016;11:e0156164.

8. West D. How mobile devices are transforming healthcare. Issues Technol Innov 2012;18:1-14.

9. Heilig GK. United Nations, Department of Economic and Social Affairs, Population Division: World Population Prospects. New York: The 2015 Revision; 2015.

10. HIMSS. HIMSS Analytics 2013 Mobile Technology Survey Examines mHealth Landscape; 2014.

11. Daim T, Pizarro M, Talla R. Planning and Roadmapping Technological Innovations: Cases and Tools. Cham: Springer; 2014.

12. Bastawrous A, Armstrong MJ. Mobile health use in low-and high-income countries: An overview of the peer-reviewed literature. J R Soc Med 2013;106:130-42.

13. Khodaei N, Kalankesh L, Sanamno Z. Scope of mobile apps in health domain: Highlighting the apps introduced by the recognized organizations. Depiction Health 2012;3:31-37.

14. Roden A. The Year of Mobile Health; 2016. Available from: http://www.datasciencecentral.com/profiles/blogs/2016the-year-of-mobile-health. Accessed on 08-03-2017.

15. Boulos M, Al-Shorbaji N. On the internet of things, smart cities and the WHO healthy cities. Int J Health Geogr 2014;13:1-6.

16. Peeples M, Iyer A, Cohen J. Integration of mobile-integrated therapy with electronic health records: Lessons learned. J Diabetes Sci Technol 2013;7:602-11.

17. García-Gómez JM, de la Torre-Díez I, Vicente J, Robles M, López-Coronado M, Rodrigues JJ. Analysis of mobile health applications for a broad spectrum of consumers: A user experience approach. Health Informatics J 2014;20:74-84.

18. Norris AC, Stockdale RS, Sharma S. A strategic approach to m-health. Health Informatics J 2009;15:244-53.

19. Patrick K, Griswold WG, Raab F, Intille SS. Health and the mobile phone. Am J Prev Med 2008;35:177-81.

20. Kalankesh L, Kalankesh L. Publication on health policy worldwide from 1898 to 2013: Identifying position of Iran. Mater Sociomed 2014;26:419-21.

21. Biglu M, Yousefi Rad K, Biglu S,Serati Nouri H. A homeopathic perspective on obstetrics and gynecology research. Int J Womens Health Reprod 2014;2:329-32.

22. Monge-Najera J, Nielsen V. The countries and languages that dominate biological research at the beginning of the $21^{\text {st }}$ century. Rev Biol Trop 2005;53:283-94.

23. Franco-Perez A, Sanz-Valero J, Wanden-Berghe C, MelianFleitas L. The iberoamerican scientific production in nutritional sciences: The indexation in pubmed and google scholar. Nutr Hosp 2014;30:1165-72

24. Ammon U. The Dominance of English as a Language of Science: Effects on Other Languages and Language Communities. New York: Walter de Gruyter; 2001.

25. Consolvo S, Klasnja P, McDonald DW, Landay JA. Designing for healthy lifestyles: Design considerations for mobile technologies to encourage consumer health and wellness. Found Trends Hum Comput Interact 2014;6:167-315.

26. Kurmis AP. Understanding the limitations of the journal impact factor. J Bone Joint Surg Am 2003;85-A:2449-54. 